\title{
Anastomotic Leak after Colorectal Surgery. Our Experience in three Years.
}

\author{
Kastriot Haxhirexha1 ${ }^{1}$ Agron Dogjani' ${ }^{2}$, Lutfi Zylbehari ${ }^{1}$, Nehat Baftiu${ }^{1}$, \\ Ferizat Dika - Haxhirexha ${ }^{1}$ \\ https://doi.org/10.32391/ajtes.v3i2.59
}

\begin{abstract}
Background: One of the most severe complication after intestinal resection, often with catastrophic consequence for the patient is leakage from the anastomosis. The severity of complications after anastomotic leak may range from a small localized peritonitis or abscess formation without sepsis, to a development of a four quadrant peritonitis with septic shock. Until now despite the seriousness of this complications, the cause of anastomotic leakage are not yet definitively clear.

Aim: The aim of this study is to submit our experience in treatment of patients with anastomotic leakage after intestinal resection and their outcome.

Materials and Methods: The study included 63 patients with colorectal cancer operated in the Department of Surgery at the Clinical Hospital of Tetova. In all patients intestinal resection with end to end anastomosis was performed.

Conclusions: Anastomotic leak after large bowel resection is a very serious complication with a great impact on patient's morbidity and mortality. Multiple risk factors are associated with occurrence of this complication whereas the more suspected are: preoperative anaemia, hypoalbuminemia, emergent surgery without adequate preparation of patient, intraoperative blood loss and blood transfusion during surgery etc. Early detection of AL is very important and helpful to improve the outcome of patients and to minimize postoperative rate of morbidity and mortality.
\end{abstract}

Keywords: anastomotic leaks, colorectal surgery, risk factors

*Corresponding Author: Kastriot Haxhirexha

=凶E-mail: $\underline{\text { dr.kastriot@gmail.com }}$

${ }^{1}$ Faculty of Medicine, University of Tetova, Department of Surgery, Clinical Hospital

Centre, Tetova Republic of North Macedonia.

2University Hospital of Trauma, Tirana, Albania 


\section{Full Text}

\section{Introduction}

Recently, intestinal resection is a common procedure performed in surgery, not only as an elective procedure but even as an emergency intervention for the benign and malignant diseases of the GI tract.

One of the most severe complication after intestinal resection, often with catastrophic consequence for the patient is leakage from the anastomosis. The severity of complications after anastomotic leak may range from a small localized peritonitis or abscess formation without sepsis, to a development of a four quadrant peritonitis with septic shock. Until now despite the seriousness of this complications, the cause of anastomotic leakage are not yet definitively clear. Some of the causes are a result of a faulty surgical technique such as intestinal ischemia at the suture line, tension across the anastomotic line, presence of local inflammatory process, and the obstruction or difficult passage distal to the anastomosis ${ }^{2,5}$. Other causes are related to the patient's state of the health such as age, coexisting disease (diabetes, systemic inflammatory disease, cardio - respiratory insufficiency, malignoma etc.), treatment with high doses of corticosteroids before surgery, chemo or radiotherapy, anaemia, malnutrition, alcohol, smoking, obesity etc $^{8}, 9$. Some of this risk factors are modifiable but most of them are permanent and can't be changed before surgery. Emergency operations are associated with a higher percentage of complications (including intestinal leakage) compared to elective ones 5 .

Anastomotic leakage is associated with abrupt clinical signs such as severe abdominal pain, fever, abdominal rigidity, tachycardia, hemodynamic instability etc. Radiological examination such as native abdominal radiography and $\mathrm{CT}$ are very important to clarify the diagnosis, especially in cases when it is uncertain.

\section{Aim of the study}

The aim of this study is to submit our experience in treatment of patients with anastomotic leakage after intestinal resection and their outcomes.

\section{Material and methods}

During 2016 - 2019 timeframe, 63 patients who had any kind of colorectal resection either elective or emergency, at the Clinical Hospital of Tetova - Department of Surgery were included in the study. We have excluded patients in whom the distal verge of tumor was been less than 15 $\mathrm{cm}$ from dental line. Important data for this study were: age, sex, chronic disease, past surgical intervention, blood count before surgery, albumin, blood urea nitrogen, serum creatinine, liver function tests and bowel preparation.

Other relevant data were duration of the operation, blood loss during surgery and intraoperative blood transfusion, and the segment of the colon in which anastomosis was performed. The anastomotic leakage was defined as leak of bowel content and of pus from the wound or through the drain. The anastomotic leakage 
was confirmed by the imaging examinations such as native abdominal radiology examination, abdominal CT with contrast and ultrasonography.

\section{Results}

The study included 63 patients with colorectal cancer operated in the Department of Surgery at the Clinical Hospital of Tetova. From 63 patients which were the subject of our study $58.7 \%$ (37) were males and $41.3 \%$ (27) females, with the average age of 64.5 years $(49-81)$. Four patients $(6.3 \%)$ were insulin dependent diabetics, eight others (12.7\%) had ischemic heart disease as a comorbidity, four patients $(6.3 \%)$ suffered from chronic

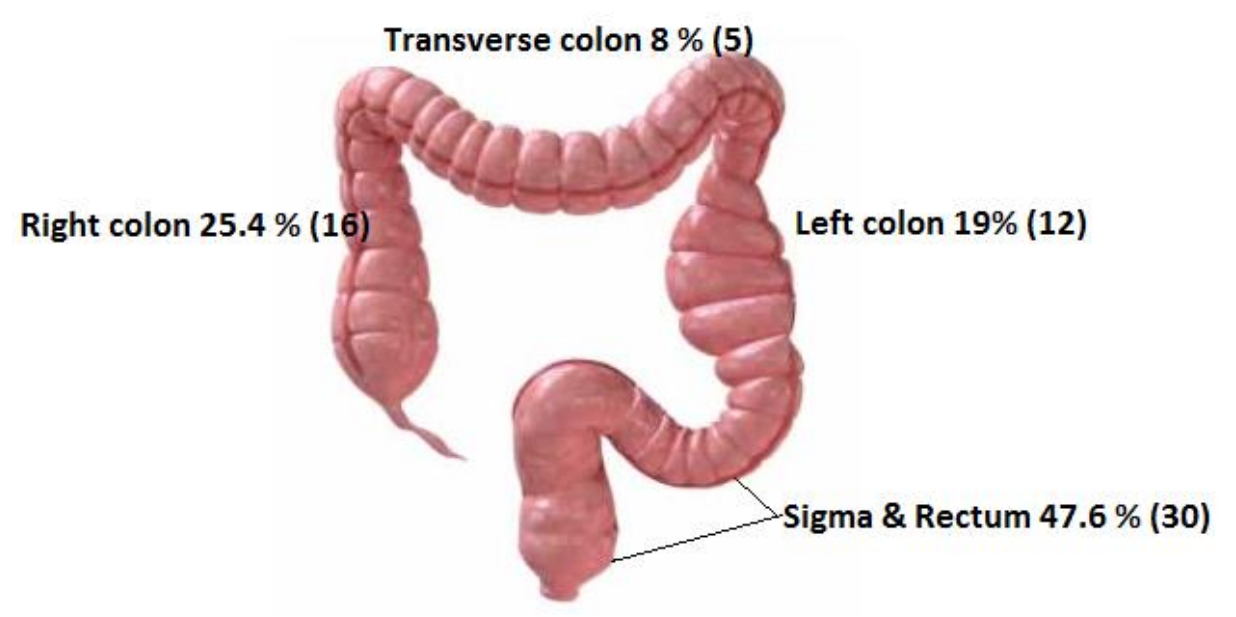

Figure 1: Localisation of tumour

In all patients intestinal resection with end to end anastomosis was performed.

Overall morbidity rate in this group of patients was $22.2 \%$ (14 patients), respectively the wound infection was pulmonary disease, 21 of them (33.3\%) were smokers, whereas five patients had undergone previous abdominal surgery. The haemoglobin level below the $12 \mathrm{gm} / \mathrm{dL}$ was registered in 19 $(30.15 \%)$ of patients, whereas albumin level under $2.5 \mathrm{gm} / \mathrm{dL}$ was registered in $16(25.4 \%)$ of the patients.

Eight patients were treated with blood transfusion before surgery, whereas three of them have received blood transfusions during surgery. Regarding the tumour localization in 16 patients $(25.4 \%)$ the tumour was localized at a right colon, in 5 patients $(8 \%)$ at the transverse colon, in 12 patients $(19 \%)$ in the left colon and in 30 patients $(47.6 \%)$ in sigma and rectum (Figure 1). 
hypoalbuminemia, anaemia, blood transfusion during surgery and the type of surgery - elective vs urgent. At the same time, men appear to be at greater risk of intestinal leakage than women (Table 1).

\begin{tabular}{llll}
\hline Condition & Totally & No leakage & Leakage \\
\hline Ischemic heart disease & 8 & $6(75 \%)$ & $2(25 \%)$ \\
\hline Pulmonary obstructive disease & 4 & $3(75 \%)$ & $1(25 \%)$ \\
\hline Insulin -dependent diabetes & 5 & $3(60 \%)$ & $2(40 \%)$ \\
\hline Smokers & 21 & $19(90.4 \%)$ & $2(9.6 \%)$ \\
\hline Gender & Male 36 & 33 & $3(9 \%)$ \\
\cline { 2 - 4 } & Female 27 & 26 & $1(3.8 \%)$ \\
\hline Previous abdominal surgery & 5 & $4(80 \%)$ & $1(20 \%)$ \\
\hline Hypoalbuminemia & 12 & $9(75 \%)$ & $3(25 \%)$ \\
\hline Anaemia & 15 & $12(80 \%)$ & $3(20 \%)$ \\
\hline Type of surgery (urgent vs elective) & Elective - 45 & 43 & 2 \\
\cline { 2 - 4 } & Urgent - 18 & 16 & 2 \\
\hline Blood transfusions during surgery & 5 & $3(60 \%)$ & $2(40 \%)$ \\
\hline
\end{tabular}

Table 1: Risk factor for anastomosis leakage

The length of hospitalization varied from seven days in uncomplicated cases to up to twenty days in cases of anastomotic leakage.

\section{Discussion}

Anastomotic leakage is the most serious complication during colorectal surgery. Clinical features of this conditions may vary from a small leak with localized circumferential peritonitis to a four quadrant generalized peritonitis with septic shock. Anastomotic leakage increases significantly the post-operative morbidity and mortality of the patients ${ }^{2,3}$.

Regardless of the gravity of this complications until now only a few data are available about the factors that induce the occurrence of this complication.

The prevalence of this complication according to many studies ranges from $2 \%$ to $20 \% 5$, whereas the most accepted definition about anastomotic leakage was: "A leak of luminal contents from a surgical join between two hollow viscera" 6, 7. The factors that can lead to this complications may be modifiable or non-modifiable. Among the modifiable factors most common are smoking, obesity, some medications, hypoalbuminemia and malnutrition, mechanical bowel preparations etc. $8,9,10$

In many studies it is estimated that malnutrition and hypoalbuminemia are a serious risk factors of $\mathrm{AL}^{11}, 12$. Therefore serious efforts must be made 
to correct these disorders before surgery. Many studies show that hypoalbuminemia alone does not increase the risk for $\mathrm{AL}$ but other factors such as metabolic disorders that lead to systemic inflammation and increased capillary permeability ${ }^{12,}{ }^{13}$. The lack of essential amino acids in patients with hypoalbuminemia may impair the synthesis of collagen and can be another factor that can affect anastomotic healing after intestinal resection ${ }^{12,14}$. In patients in whom it is not possible to correct hypoalbuminemia is better to avoid anastomosis and to perform colostomy.

Anemia causes a fall in the supply of the intestinal submucosa with oxygen. That may cause the dehiscence and leak of the anastomosis7. Even in our study hypoalbuminemia and anemia results to be a risk factor for AL.

Blood transfusion especially during surgery increase the formation of micro thrombosis in small vessels which in anastomotic area may lead to dehiscence and anastomotic leak ${ }^{7}$.

In this study, emergency surgery is associated with increased risk of AL. Similar data have been reported by Mc

\section{References}

1. Bruce J, Krukowski ZH, AlKhairy G et al (2001). Systematic review of the definition and measurement of anastomotic leak after gastrointestinal surgery. $\mathrm{Br} \mathrm{J}$ Surg. 88(9):1157- 68

2. Bieleki K and Gajda A (1999). The causes and prevention of anastomotic leak after colorectal surgery: Klinickaonkology; 2530
Dermott and Bakker in their studies ${ }^{13}$, 15.

\section{Conclusions}

Anastomotic leak after large bowel resection is a very serious complication with a great impact on patient's morbidity and mortality. Multiple risk factors are associated with occurrence of this complication whereas the more suspected are: preoperative anaemia, hypoalbuminemia, emergent surgery without adequate preparation of patient, intraoperative blood loss and blood transfusion during surgery etc. The clinical features of AL vary from small pelvic abscess to the severe generalized peritonitis with the leak of pus and bowel content through the drain or the wound.

Early detection of AL is very important and helpful to improve the outcome of patients and to minimize postoperative rate of morbidity and mortality.

3. Chambers WM and Mortensen NJ (2004). Postoperative leakage and abscess formation after colorectal surgery. Best Pract Res Clin Gastroenterol; 18 (5): 865-80.

4. Jung SH, Yuc S, Choip W et al (2008). Risk factors and oncolgic impact of anastomtic leakage after rectal cancer surgery. Dis colon rectum; 51: 902- 908.

5. Daams F, Luyer M and Lange JF (2013). Colorectal anastomotic 
leakage: aspects of prevention, detection and treatment. World J Gastroenterol; 19(15):2293-7

6. Wille-Jørgensen P, Guenaga KF, Matos D et al (2005). Preoperative mechanical bowel cleansing or not? an updated meta-analysis. Colorectal Dis. 7(4):304-10.

7. Kiran RP, Delaney CP, Senagore AJ et al (2004). Operative blood loss and use of blood products after laparoscopic and conventional open colorectal operations. Arch Surg. 139(1):39-42

8. T, Watanabe $\mathrm{T}$, Kishimoto J, Nagawa H. Risk factors for anastomotic leakage for colorectal cancer: Results of prospective surveillance. J Am Coll Surg. 2006;202:439-44

9. Iancu C, Mocan LC, TodeaIancu D, Mocan T, Acalovschi I, Ionescu D, et al. Host-related predictive factors for anastomotic leakage following large bowel resections for colorectal cancer. J Gastrointestin Liver Dis. 2008;17:299-303.

10. McDermott FD, Heeney A, Kelly ME, Steele RJ, Carlson GL, Winter DC. Systematic review of preoperative, intraoperative and postoperative risk factors for colorectal anastomotic leaks. Br J Surg 2015;102(5):462-79. Doi: $10.1002 /$ bjs. 9697.

11. Bakker IS, Grossmann I, Henneman D, Havenga K, Wiggers T. Risk factors for anastomotic leakage and leak related mortality after colonic cancer surgery in a nationwide audit. Br J Surg 2014; 101(4):42432. Doi: 10.1002ébsj.9395.

12. Boccola MA, Buettner PG, Rozen WM, Siu SK, Stevenson AR, Stitz R, Ho YH. Risk factors and outcomes for anastomotic leakage in colorectal surgery: a single-institution analysis of 1576 patients. World J Surg 2011;35(1):186-95. Doi: 10.1007/ s00268-010-0831-7.

13. Frasson M, Flor-Lorente B, Rodriguez JL, Granero-Castro P, Hervas D, Alvarez Rico MA, et al. Risk Factors for Anastomotic Leak After Colon Resection for Cancer : Multivariate Analysis and Nomogram From a Multicentric, Prospective, National Study With 3193 Patients. Ann Surg 2015;262(2):321-30. Doi: 10.1097/SLA.0000000000000973

14. Parthasarathy M, Greensmith M, Bowers D, Groot - Wassink $\mathrm{T}$. Risk factors for anastomotic leakage after colorectal resection: a retrospective analysis of 17518 patients. Colorectal Dis 2017; 19(3):288298. Doi: $10.1111 /$ codi.13476

15. Kirchhoff P, Clavien PA and Hahnloser $\mathrm{D}$ (2010).Complications in colorectal surgery: risk factors and preventive strategies. Patient Saf Surg.4(1):5. 
